\title{
Comparison of Different Cultivars of Blueberry Overwintering Ability in Qingdao of China
}

\author{
Wan-Ping Liu, Shu-Chai Su, Xiao Liu, Zhi-Xia Hou
}

The Key Laboratory for Silviculture and Conservation, Beijing Forestry University, Beijing, China.

Email: penguin.1wp@163.com

Received November $24^{\text {th }}, 2011$; revised December $23^{\text {rd }}, 2011$; accepted January $11^{\text {th }}, 2012$

\begin{abstract}
In order to select severe overwintering abilitied blueberry cultivars for cold resistance of annual branches, promoting breeding high quality cultivars, a study had been conducted into field-planting shoots overwintering ability and the relative conductivity, MDA content, SOD of 7 different kinds of blueberries under artificial cooling process. According to survey results, under field conditions, Different cultivars of blueberries showed significantly difference, ranging from $56.67 \%$ of Bluegold to $12.80 \%$ of Darrow. With the temperature decreasing, changes of relative conductivity, MDA content and SOD in annual branches had a strong regularity and the hardiness of these cultivars is: Northland $>$ Chippewa $>$ Coville $>$ Bluecroup $>$ Darrow $>$ Bluegold $>$ Powderblue.
\end{abstract}

Keywords: Blueberry; Cultivars; Overwintering Ability; Annual Branch

\section{Introduction}

Overwintering of blueberry is closely related to such factors as low winter temperature and physiological drought in early spring, and its overwintering ability shows a wide range of differences attributed to many kinds of natural climate conditions and artificial cultivation measures; even in the same type of climate, there are significant differences between different cultivars. Overwintering ability is an important index to measure environmental suitability of plants. Therefore, field survey and determination of physiological and biochemical indexes to evaluate the overwintering ability of fruit trees have been widely used in many species. Currently, deep studies at home and abroad have been conducted into overwintering ability of American almond [1], red raspberry [2], ribes nigrum [3], apricot [4], walnut [5], pepper [6], etc.

Blueberry is a Vaccinium plant of Ericaceae, most of which are frutex and a few are arbor. Mature blueberry fruit is dark blue to violet, and it is one of the extremely few plants producing really blue fruits [7]. Blueberry attracts wide attention in the international market for its unique health care nutritional value, which has been listed as one of the five major health foods by the United Nations Food and Agriculture Organization and is dubbed as the king of the third-generation fruits in the world [8]. However, most domestic cultivars belong to the North American cultivar; although the main culti- vation areas in China's Shandong peninsula and America, the climates are still significantly different, especially part of introduced cultivars cannot adapt well to the low winter temperature of Shandong peninsula. For this purpose, this study is designed and finished to make an analysis on cold resistance of main 7 cultivars of blueberries in Iiaonan area, Qingdao so that it can lay a foundation for further cultivation and breeding and provide theoretical basis for sustainable and healthy development of blueberry.

\section{Materials and Methods}

\subsection{Materials and Sampling Method}

\subsubsection{General Situation of Test Site and Selection of Materials}

Test materials are taken from Panjiazhuang base of Wolin Agriculture (Qingdao) Co., Ltd. and the test site is located in Jiaonan, Qingdao, Shandong, where it is maritime monsoon climate with moderate annual rainfall, cool and wet in summer, cold and wet in winter, four seasons clear, 202 days of frost-free period, and 2447.1 hours sunshine each year. Average annual rainfall is $798.3 \mathrm{~mm}$, annual rainy days is $83-97$ and temperature is $\geq 10^{\circ} \mathrm{C}$; average rainstorm days is $2-4$, average annual humidity is above $70 \%$, and the relative humidity there is the highest in the whole province. Average annual temperature is $12.1^{\circ} \mathrm{C}$, the lowest temperature in a year is $-10^{\circ} \mathrm{C}$ and the highest temperature is $36^{\circ} \mathrm{C}$. 
The survey on overwintering started in March 2011 at Panjiazhuang base. In 2011, the lowest temperature reached $13.0^{\circ} \mathrm{C}$, which appeared on January $16,1.1^{\circ} \mathrm{C}$ lower than the lowest temperature $-11.9^{\circ} \mathrm{C}$ in 2010 and $2.5^{\circ} \mathrm{C}$ lower than the lowest temperature $-10.5^{\circ} \mathrm{C}$ in 2009 .

The test objects include Bluecroup ((Jersey $\times$ Pioneer) $\times($ Stanley $\times$ June) $)$, Bluegold () , Coville $($ GM37 $\times$ Stanley), Chippewa (), Darrow ((Wareham $\times$ Pioneer $) \times$ Bluecroup), Northland (Berkeley $\times$ (Lowbush X Pioneer)) and Powderblue (Tifblue $\times$ Menditoo). The sampling object is annual branches of 5 - 6 year-old trees that grow well.

\subsubsection{Sampling Method}

In March 2011, a survey and grading was conducted on the overwintering situation of all cultivars in the field. In late December 2010, the moderate plants that grew even were selected to collect randomly the annual branches $30 \mathrm{~cm}$ long without diseases and insect pests on the upper parts and they were then brought back to the lab for low temperature stress and determination of cold resistance indexes.

\subsection{Test Method}

\subsubsection{Survey on Overwintering of Different Cultivars in the Field}

The test is designed for complete random of individual plant, repeated for 15 times, and the survey object is $5-6$ year-old trees. The test adopts a "z" sampling method, and only one branch is selected from four directions (east, west, south and north) of each tree. The specific grading standard of injury rate is as follows: Grade 0 : no sprouting; Grade 1: annual branch partially wrinkled; Grade 2: annual branch mostly wrinkled and dried; Grade 3: annual branch all dried up; Grade 4: part above the ground is all sprouted up. According to grading standard, an analysis is to be made on the situation of sprouting of the branches of all cultivars after survey.

\subsubsection{Low Temperature Stress Process}

The test is designed adopt completely random method, each process repeated for 3 times. The sampling object is the annual branches of $5-6$ year-old trees that grow well. Clean the picked branches with distilled water; after the water is blot up, bind them respectively and put them in a refrigerator for artificial simulated cooling process. The processing temperatures are respectively $-8^{\circ} \mathrm{C},-16^{\circ} \mathrm{C}$ and $-24^{\circ} \mathrm{C}$. Cooling rate is $2^{\circ} \mathrm{C} \cdot \mathrm{h}^{-1}$, and after they are frozen for $12 \mathrm{~h}$, take $20 \mathrm{~g}$ every time for determination of related indexes.

\subsubsection{Index Determination}

Leakage rate of electrolyte: conductance method is ado- pted for determination [9].

MDA content: TBA method is adopted for determination of MDA content [10].

SOD activity: NBT method is adopted to determine SOD activity [11].

Data analysis: Excel is adopted for original data processing and SPSS19. 0 is adopted for analysis.

\section{Results and Analysis}

\subsection{Survey on Sprouting of Blueberry Branches}

After the winter, different cultivars of blueberry branches are different in injury symptoms. Among them, annual branches suffer the most. Those suffer the least have mostly wrinkled skins where the buds are wizened, and what is even worse it that the wrinkle is so serious that it covers the whole branch that turns into grey brown, and the buds thereon is wizened to death, even endangering the two-year and three-year branches. Freeze injury is getting worse and worse from winter to spring, and therefore, the withering due to freeze injury is from the lower part to the upper part and happens in the winter season. Sprouting also could lead to death, but it is from the upper part to the lower part, which happens from the middle and late February to the middle and late March when the temperature rises, it is dry, windy and turns cold again after suddenly getting warmer [12]. The wind force at the test site can reach level 7, and most branches of blueberries there die from the upper part to the lower part, which also happens from February to March. From this, we can make a judgment that sprouting is the major reason that causes injuries to the blueberries for overwintering.

For injury degrees of 7 cultivars of blueberries by the survey in March 2011, see Figure 1 and Table 1.

By analysis of variance, sprouting of different cultivars is significantly different. Among them, Bluegold suffers the most, reaching $56.67 \%$. The sprouting of Bluegold often occurs to annual branches that are dried up. The percent of sprouting of Bluecroup is only $25.00 \%$ whereas it appears on many main branches that are wholly dried up. Among them, the percent of sprouting of Darrow is the least, which is only $12.80 \%$.

\subsection{Low Temperature Stress's Impact on the Conductivity of Annual Branch of Blueberry}

With the strengthening of low temperature stress, peroxidation of plant cell membrane lipid is strengthened, and the membrane permeability is increased, leading to solute leakage, and conductivity increase. The relative electric conductivity reflects how much cell membrane suffers. The higher the relative conductivity, the more injury the plant body suffers. Therefore, the leakage con- 


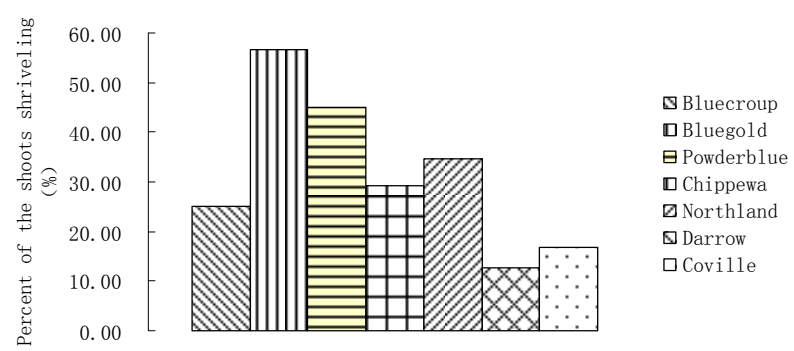

Figure 1. Percent of the shoots shriveling of 7 cultivars.

Table 1. Data of the shoots shriveling of 7 cultivar at the low temperature level.

\begin{tabular}{cccc}
\hline Cultivar & Average Value & Alpha $=0.5$ & Alpha $=0.1$ \\
\hline Bluegold & 56.67 & $\mathrm{a}$ & $\mathrm{A}$ \\
Powderblue & 45.00 & $\mathrm{~b}$ & $\mathrm{~B}$ \\
Northland & 34.63 & $\mathrm{c}$ & $\mathrm{C}$ \\
Chippewa & 29.17 & $\mathrm{~d}$ & $\mathrm{D}$ \\
Bluecroup & 25.00 & $\mathrm{e}$ & $\mathrm{E}$ \\
Coville & 16.70 & $\mathrm{e}$ & $\mathrm{E}$ \\
Darrow & 12.80 & $\mathrm{f}$ & $\mathrm{F}$ \\
\hline
\end{tabular}

ductivity method has become a common method for study on cold resistance of fruit trees [13].

For measured conductivity of 7 cultivars of blueberries at $0^{\circ} \mathrm{C},-8^{\circ} \mathrm{C},-16^{\circ} \mathrm{C}$ and $-24^{\circ} \mathrm{C}$, see Figure 2 and Table 2.

As the temperature lowers, annual branches of all cultivars suffer more and more injuries and the conductivity also significantly increases, but there exists a certain differences for different cultivars at different temperatures. When the temperature reaches $-16^{\circ} \mathrm{C}--24^{\circ} \mathrm{C}$, the injury as a result of low temperature to all cultivars declines, and the annual branches are not dead; however, the conductivity of all cultivars has reached $57.82 \%-75.29 \%$. From Figure 2, we can see when it is $0^{\circ} \mathrm{C}-8^{\circ} \mathrm{C}$, low temperature causes the most injuries to Northland and Chippewa and conductivity increase is the biggest, which is up to 0.5842 times and 0.5454 times, while the increase of Powderblue is the least, which is only 0.0008 times; when it is $-8^{\circ} \mathrm{C}-16^{\circ} \mathrm{C}$, low temperature causes the least injuries to Northland and Chippewa, which is 0.4885 times and 0.2294 times, but low temperature causes the most injuries to other cultivars, of which the conductivity increase of Powderblue is the biggest, up to 0.8554 times; when it is $-8^{\circ} \mathrm{C}--16^{\circ} \mathrm{C}$, most cultivars suffers the most; When it is $-16^{\circ} \mathrm{C}--24^{\circ} \mathrm{C}$, the injury due to low temperature to all cultivars declines, but the conductivity of different cultivars has been up to $57.82 \%$ $-75.29 \%$, which suggests that when it is $-24^{\circ} \mathrm{C}$, the in vitro tissues of all cultivars have been seriously injured,

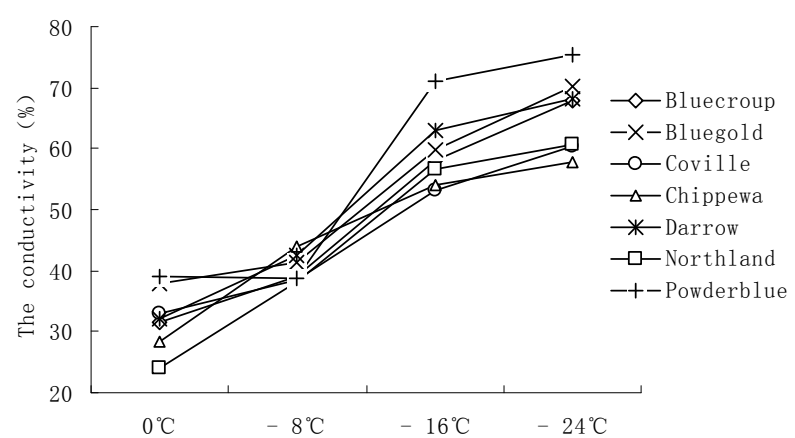

Figure 2. The conductivity of 7 cultivars at the different low temperature level.

Table 2. Data of the conductivity of 7 cultivar at the low temperature level.

\begin{tabular}{cccc}
\hline Cultivar & Average Value & Alpha $=0.5$ & Alpha $=0.1$ \\
\hline Powderblue & 56.01 & $\mathrm{a}$ & $\mathrm{A}$ \\
Bluegold & 52.26 & $\mathrm{~b}$ & $\mathrm{~B}$ \\
Darrow & 51.47 & $\mathrm{c}$ & $\mathrm{C}$ \\
Bluecroup & 49.18 & $\mathrm{~d}$ & $\mathrm{D}$ \\
Coville & 46.29 & $\mathrm{e}$ & $\mathrm{E}$ \\
Chippewa & 46.06 & $\mathrm{e}$ & $\mathrm{E}$ \\
Northland & 44.88 & $\mathrm{f}$ & $\mathrm{F}$ \\
\hline
\end{tabular}

the membrane permeability is destroyed and most electrolyte in the cell leaks especially the leakage rates of electrolytes of Powderblue and Bluegold, which are above $70 \%$. After analysis of variance on freeze injury degree, there is significant difference between all cultivars. Based on the conductivity values in Figure 1, we can draw a conclusion that the resistances of 7 cultivars of blueberries are different and the sequence from high to low is Northland $>$ Chippewa $>$ Coville $>$ Bluecroup $>$ Darrow $>$ Bluegold $>$ Powderblue.

\subsection{MDA Measurement for Annual Branch of Different Cultivars}

MDA is the end product of membrane lipid peroxidation and its content is an important index for the strength of membrane lipid peroxidation. Many researches suggest that the MDA content in plant materials can be adopted to evaluate the cold resistance of the plant [14].

See Figure 3 and Table 3 for MDA measurement results of 7 cultivars at difference temperature level of normal temperature $(\mathrm{CK}), 0^{\circ} \mathrm{C},-8^{\circ} \mathrm{C},-16^{\circ} \mathrm{C}$ and $-24^{\circ} \mathrm{C}$.

The variance analysis results for MDA content of every cultivar under different low temperature level show a significant difference. All their contents gradually increase except that of Bluegold. As can be seen from Ta- 


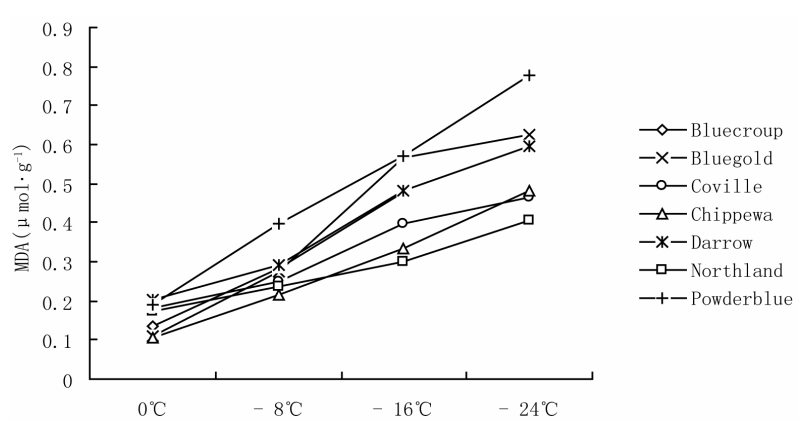

Figure 3. The MDA of 7 cultivar at the different low temperature level.

Table 3. Data of the MDA of 7 cultivar at low temperature level.

\begin{tabular}{cccc}
\hline Cultivar & Average Value & Alpha $=0.5$ & Alpha $=0.1$ \\
\hline Powderblue & 0.4839 & $\mathrm{a}$ & $\mathrm{A}$ \\
Bluegold & 0.3974 & $\mathrm{~b}$ & $\mathrm{~B}$ \\
Darrow & 0.3939 & $\mathrm{~b}$ & $\mathrm{~B}$ \\
Bluecroup & 0.3914 & $\mathrm{~b}$ & $\mathrm{~B}$ \\
Coville & 0.3308 & $\mathrm{c}$ & $\mathrm{C}$ \\
Chippewa & 0.2841 & $\mathrm{~d}$ & $\mathrm{D}$ \\
Northland & 0.278 & $\mathrm{~d}$ & $\mathrm{D}$ \\
\hline
\end{tabular}

ble 2, MDA content of every cultivar increases significantly as the decrease of the temperature and increases very rapidly at the low temperature of $0^{\circ} \mathrm{C}$ to $-8^{\circ} \mathrm{C}$, among which Bluegold has the largest increase rate and amounts to $153 \%$. At $-8^{\circ} \mathrm{C}$ to $-16^{\circ} \mathrm{C}$, MDA content in annual branch of all cultivars increases significantly except Northland. Bluegold has the largest increase rate of $271 \%$. Annual branch of every cultivar shall be damaged in largest degree at $-8^{\circ} \mathrm{C}$ to $-16^{\circ} \mathrm{C}$. The MDA content in Bluegold is still increased most rapidly at $-16^{\circ} \mathrm{C}$ to $-24^{\circ} \mathrm{C}$ and amounts to $81.44 \%$. But Powderblue has the highest MDA content which amounts to $0.5688 \mu \mathrm{mol} \cdot \mathrm{g}^{-1}$. After variance analysis and multiple comparisons, the MDA content of annual branch of Powderblue, Bluegold, Darrow, Bluecroup, Coville, Chippewa and Northland is the four levels with the gradual reduction. The unsaturated fatty acids in plant cell membrane are directly related to the cold resistance strength. Lipid peroxidation occurs to most unsaturated fatty acids of the plant under the action of reactive oxygen at low temperature [11]. Membrane lipid peroxidation often occurs when the plant organ is aged or at adverse conditions and the produced MDA by it shall seriously damage the biofilm. It is usually adopted as membrane lipid peroxidation index to display the cell membrane lipid peroxidation and strength to the adverse conditions. The higher of MDA content, the weaker of plant's cold resistance and vice versa [15]. Table 2 shows that MDA content of 7 cultivars are different. Therefore, their hardiness is: Northland $>$ Chippewa $>$ Coville $>$ Bluecroup $>$ Darrow $>$ Bluegold $>$ Powderblue.

\subsection{SOD Measurement for Annual Branch of Different Cultivar}

Under normal conditions, the production and elimination of the free radicals $\left(\mathrm{O}_{2}^{-}-, \cdot \mathrm{O}_{2}, \cdot \mathrm{OH}\right.$ and $\mathrm{H}_{2} \mathrm{O}_{2}$ etc. $)$ in the plant cells are in balance so as to keep the stability of cell membrane system and maintain the normal physiological metabolic activity. When the plant is in a variety of adverse stress, this balance shall be destroyed and the free radicals shall be accumulated, which then causes or exacerbates membrane lipid peroxidation, results in membrane system damage and cause cell death in serious conditions [16]. SOD is the main enzyme in the plant to eliminate free radicals. Its activity reflects the adaptability of the cell to the adverse conditions and indirectly indicates the cold resistance of the plant.

See Figure 4 and Table 4 for SOD measurement results of 7 cultivars at difference temperature level of normal temperature $(\mathrm{CK}), 0^{\circ} \mathrm{C},-8^{\circ} \mathrm{C},-16^{\circ} \mathrm{C}$ and $-24^{\circ} \mathrm{C}$.

In plant cells, $\mathrm{SOD}$ is mainly used to eliminate the su-

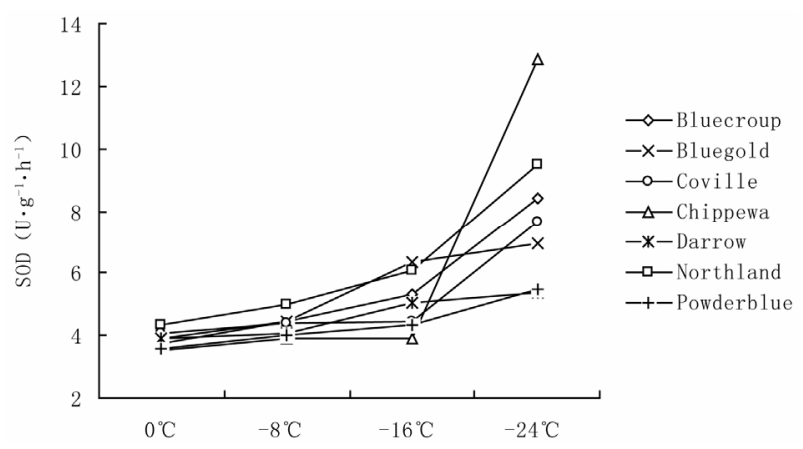

Figure 4. The SOD of 7 cultivar at the different low temperature level.

Table 4. Data of the SOD of 7 cultivar at low temperature level.

\begin{tabular}{cccc}
\hline Cultivar & Average Value & Alpha $=0.5$ & Alpha $=0.1$ \\
\hline Chippewa & 6.2294 & $\mathrm{a}$ & $\mathrm{A}$ \\
Northland & 6.0414 & $\mathrm{~b}$ & $\mathrm{~B}$ \\
Coville & 5.4666 & $\mathrm{c}$ & $\mathrm{C}$ \\
Bluecroup & 5.4086 & $\mathrm{c}$ & $\mathrm{C}$ \\
Darrow & 5.1377 & $\mathrm{~d}$ & $\mathrm{D}$ \\
Bluegold & 4.5725 & $\mathrm{e}$ & $\mathrm{E}$ \\
Powderblue & 4.3516 & $\mathrm{f}$ & $\mathrm{F}$ \\
\hline
\end{tabular}


peroxide free radicals. After variance analysis, the SOD content of the same cultivar at different low temperature is significantly different. As can be seen from Figure 3, the law of the SOD content of every cultivar changing with the decrease of temperature is different. The SOD content of Bluegold and Darrow increase most rapidly at $-8^{\circ} \mathrm{C}$ to $-16^{\circ} \mathrm{C}$, which amounts to $41.79 \%$ and $24.39 \%$ respectively, and increase relatively slow at the low temperature of $0^{\circ} \mathrm{C}$ to $-8^{\circ} \mathrm{C}$. However, the SOD content of annual branch of other 5 cultivars increases most rapidly at $-16^{\circ} \mathrm{C}$ to $-24^{\circ} \mathrm{C}$. From the perspective of cultivar, SOD content of annual branch of Chippewa can still amount to $12.872 \mathrm{U} \cdot \mathrm{g}^{-1} \cdot \mathrm{h}^{-1}$ at temperature down to $-24^{\circ} \mathrm{C}$ while that of Powderblue is only $5.4907 \mathrm{U} \cdot \mathrm{g}^{-1} \cdot \mathrm{h}^{-1}$. Therefore, under low temperatures stress, SOD activity is positively correlated with cold resistance of different cultivar, i.e. the higher of cold resistance ability of different cultivar, the higher the SOD activity and vice versa. The hardiness of the 7 cultivars is: Chippewa $>$ Northland $>$ Coville $>$ Bluecroup $>$ Darrow $>$ Bluegold $>$ Powderblue.

\section{Discussions}

Sprouting occurs because that spring is windy and dry. After it becomes warm in early spring, the fruit trees transpire strongly. However, the soil thaws late and it is difficult for the root to absorb water, which thus cause the serious imbalance between the root water absorption and the branch transpiration and the tree sprouts seriously [17]. The sprouting of blueberries in the experiment field often occurs to annual branch. For the blueberry bud separation has been completed in the previous year, the sprouting has relatively adverse effects for the flowering and fructification of the next year. Smearing anti-sprouting agent, enhancing water and fertilizer management in autumn and windproof treatment in winter can effectively prevent the occurrence of sprouting.

In this experiment, the general trend for relative conductivity change of all experimented varieties is that the relative conductivity shall gradually increase as the decrease of the temperature. Plasmalemma may be the original position for damage by low temperature. Changes in cell membrane permeability are the key to the impact of low temperature stress. Low temperature causes membrane damage and results in changes and loss of semipermeability of the membrane. Large amount of the materials within the cell leaks and cause the cell death at last. Therefore, the damage degree and cold resistance of the plant can be reflected by permeability changes of the electrolyte under the low temperature. Permeability of electrolyte within the membrane is represented by relative conductivity before and after low temperature damage. It is found in the experiment that Northland and
Chippewa have been damaged in smallest degree at $-8^{\circ} \mathrm{C}$ to $-16^{\circ} \mathrm{C}$ while damage of other cultivars are increased, which reflects that the two cultivars have strong adaptability to low-temperature environment and strong cold resistance ability. In addition, it is found in the experiment that it is dramatically increased after reaching a certain temperature point which is $-16^{\circ} \mathrm{C}$ for most cultivars. The relative conductivity value is different for different cultivars, which reflects the resistance differences of different cultivars. The electrolyte permeability peak of the cultivars with weak cold resistance appears earlier. The results are more consistent with the previous studies. MDA is the end product of lipid peroxidation. The content of it can reflect the damage degree of the cell [18]. In this experiment, the MDA content of various cultivars gradually increases along with the decrease of the temperature. But the increase range between different temperature segments is different. MDA content increases most rapidly at $-8^{\circ} \mathrm{C}$ to $-16^{\circ} \mathrm{C}$ (except Northland) and increases most slowly at $0^{\circ} \mathrm{C}$ to $-8^{\circ} \mathrm{C}$ and $-16^{\circ} \mathrm{C}$ to $-24^{\circ} \mathrm{C}$, which reflects that annual branch obtains the most serious damage at the low temperature of $-8^{\circ} \mathrm{C}$ to $-16^{\circ} \mathrm{C}$. Membrane lipid peroxidation is enhanced; the permeability of the membrane increases and the shoot was seriously hurt. SOD is the key protective enzyme of the enzyme defense system in plant enzymatic lipid peroxidation. In the cell protective enzyme, SOD can remove superoxide radicals and maintain the integrity and stability of the cell. Low temperature decreases the enzyme activity and makes the $\mathrm{O}_{2}^{-}$in the plant increase, which is confirmed in banana (Musa nana Lour.) and plantains (M. sapientum L.) [19] and other plants. In the research, SOD activity of the annual branch of tested cultivars is tended to increase along with the decrease of the temperature. The conductivity hasn't increased rapidly at $16^{\circ} \mathrm{C}$ to $24^{\circ} \mathrm{C}$ but SOD content still increases rapidly. It is suspected that the temperature is decreased slowly. Sample and put it into liquid $\mathrm{N}$ after it decreases to a certain temperature. Froze quickly and sample enzyme. However, different changes for different cultivars can be displayed form the results of variance analysis. Integrating the above three indicators, the hardiness of these cultivars is: Northland $>$ Chippewa $>$ Coville $>$ Bluecroup $>$ Darrow $>$ Bluegold $>$ Powderblue.

Integrating all indexes, the annual branch of various cultivars are damaged slightly at $0^{\circ} \mathrm{C}$ to $-8^{\circ} \mathrm{C}$. But the damage become serious after exceeding $-8^{\circ} \mathrm{C}$. The critical temperature of the branch under experimental conditions is $-8^{\circ} \mathrm{C}$ to $-16^{\circ} \mathrm{C}$. Its lower limit can cause ireversible damage. The lowest temperature in the experiment field in 2011 amounts to $-13^{\circ} \mathrm{C}$ and the wind speed of the experiment field is up to Level 7. Therefore, sprouting often occurs. Combining with the experiment field performance and the measured results analysis of 
physical signs under indoor control environment, Powderblue and Bluegold are not only seriously damaged but also have serious sprouting. Therefore, enriching the limb before the plant entering into dormancy period and enhancing water and fertilizer management in autumn etc can improve the cold resistance of the blueberry branches and are the keys to ensure the normal overwintering.

\section{Acknowledgements}

This study was supported by State Forestry Administration Key Project "Special Fund for Scientific Research of Provincial Forestry Public Benefit Industry," "Study on Directional and Efficient Cultivation and Processing Application Technology of Blueberry (200904014)."

\section{REFERENCES}

[1] S. Wang, B.-X. Xie, H.-Y. Du, Q.-P. Zhong and S.-B. Yang, "Study on Coldness Resistance of Flower in Almond," Nordwood Forest Research, Vol. 25, No. 2, 2007, pp. 19-22.

[2] Z.-J. Xue, H.-P. Dai, Q. Tang and B.-L. Su, "Study on Overwintering Ability of Red Raspberry," Journal of Shenyang University, Vol. 19, No. 6, 2007, pp. 32-35.

[3] Q.-Y. Gao, J. Wang, Y. Ma and Y.-H. Zhang, "Relationship of Variation of Organic Matters and Winterhardiness of Blackcurrant," Journal of Northeast Agricultural University, Vol. 28, No. 3, 1997, pp. 238-242.

[4] S.-H. Guo, Q. Yang, X.-L. Yang, Y.-F. Liu, J.-C. Qi and Y.-M. Bi, "Effects of Salicylic Acid on Cold Resistance during Flowering Period and Fruit Sitting Rate in Apricot," Nordwood Forest Research, Vol. 25, No. 4, 2007 , pp. 24-27.

[5] G.-P. Liu, S.-H. Wang, B.-J. Zhao and Z.-A. Liu, "Cold Resistance of Annual Branches in Walnut," Nordwood Forest Research, Vol. 28, No. 4, 2010, pp. 108-111.

[6] X.-F. He, T.-X. Yang and A.-Z. Wei, "Changes of Physiological Indexes of Zanthoxylum bungeanum Related to Cold Resistance during Natural Overwintering," Journal of Northeast Forestry University, Vol. 37, No. 5, 2009 pp. 67-69.

[7] Y. Gu, "Blueberry and Granberry," China Agricultuer Press, Beijing, 2001.

[8] F. Nie, J.-M. Wai and G.-Q. Wen "Discussion on Economical Values of Vaccinium ssp. and Its Industrial De- velopment Prospect in China," Guizhou Agricultural Sciences, Vol. 35, No. 1, 2007, pp. 117-119.

[9] Q.-H. Shi, J.-S. Gao and J. Wang, "Determination and Evaluation of Cold Resistance of 5 Poplar Clones," Acta Botanica Boreali-Occidentalia Sinica, Vol. 23, No. 11, 2003, pp. 1937-1941.

[10] J.-F. Niu, Z.-P. Wang and G. Li, "Comparison of Different Methods for Examination of Grape Hardiness," Journal of Fruit Science, Vol. 23, No. 1, 2006, pp. 31-34.

[11] Q.-R. Meng, "Studies of Cold Resistance in Apricot," Master's Thesis, Agricultural University of Hebei, Baoding, 2002.

[12] C.-N. Li, F.-X. Dong, R.-Q. Zhang, G. X. Wang and L. S. Liang, "Research Progress in the Study of Shoot Shriveling in Fruit Trees" Chinese Agricultural Science Bulletin, Vol. 26, No. 3, 2010, pp. 138-141.

[13] J.-M. Yang, Y.-H. Li, M.-S. Yang, F.-Z. Sun, T.-C. Zhao and Z.-S. Zhu, "Comparative Study on Cold Resistance of Apricot Varieties" Scientia Agricultura Sinica, Vol. 32, No. 1, 1999, pp. 46-50.

[14] F. J. Yang, B. J. Li and Y. G. Gao, "Recentprogress in the Study of Cold Resistance of Fruit Tree," Heilongjiang August First Land Reclamation University, Vol. 15, No. 4, 2003, pp. 23-29.

[15] Z. Shi, "Research of Cold Resistance Physiological Characteristics of Three Ziziphus Varieties," Master's Thesis, Agricultural University of Hebei, Baoding, 2003.

[16] W.-H. Xu, L.-L. Wang and Z.-G. Wang, "Effects of low Temperature on Physiological and Biochemical Characteristics of Pepper Seedlings," Journal of Gansu Agricultural University, Vol. 40, No. 4, 2005, pp. 475-479.

[17] F. Zhang and B.-R. Wang, "Efects of Diffent Protectants on Preventing Shoots from Shriveling onYoung Apple Tree When Overwintering," Journal of Beijing Forestry University, Vol. 20, No. 1, 1998, pp. 89-92.

[18] C.-L. Xiao, Y.-K. Wang, C.-Y. He, Y.-Z. Li and G.-Z. Zhang, "Studies on the Relationship between the Changes of Mian Physiological Indices and Cold-Resistance in the New Shoots of Dahongpao Zanthoxylum bungeanum under Low Temperature Stress," Journal of Anhui Agricultural Sciences, Vol. 36, No. 10, 2008, pp. 3975-3977.

[19] B.-Y. Zhou, L.-F. Liang, H.-B. Huang and Z.-H. Wang, "Effects of Low Temperature and Paclobutrazol on Superoxide Dismutase and Abscisic Acid of Bananas (Musa spp.)," Acta Horticulturae Sinica, Vol. 2, No. 4, 1995, pp. 31-33. 